\title{
Concept of Poverty in a Rural Community: A Qualitative Study of the Views of Magobbo Smallholder Farmers in Zambia's Mazabuka District
}

\author{
Thomson Kalinda (Corresponding author) \\ Department of Agricultural Economics and Extension, University of Zambia \\ Great East Road Campus, P.O. Box 32379, Lusaka, Zambia
}

Tel: 260-0966-454366Ｅ-mail: thomsonkalinda@gmail.com

Received: June 3, 2014 Accepted: July 2, 2014 Published: August 8, 2014

doi:10.5296/ijssr.v2i2.5741 URL: http://dx.doi.org/10.5296/ijssr.v2i2.5741

\begin{abstract}
The objective of this study was to obtain an understanding of local views on the characteristics of poor and wealthy households, as perceived by the rural residents. The study was conducted in Magobbo area which is located in Mazabuka District in Zambia's Southern Province. Qualitative research methods and techniques, including Participatory Wealth Ranking (PWR) exercises were used to generate information on the traits, characteristics and visible signs by which poverty is recognized by people in the area. The results show that the rural residents were clearly able to identify several characteristics or themes to describe the poverty or wealth status of households in Magobbo. Livelihood activities or employment status was identified by the residents as one of the main characteristic in describing the relative poverty or wealth status of households. The physical assets owned; land ownership or tenure; housing conditions; food security; schooling of children; and alternative income generation activities such as begging, and getting remittances from relatives were also identified. A variety of other non-income characteristics were also identified such as the gender dimension of poverty, as well as the health and nutrition status of the households. These findings show that PWR exercises are useful in capturing local knowledge about poverty and in identifying or defining who the poorest are in rural areas. Such information is important in making decisions related to identifying, targeting, planning and prioritizing of interventions for addressing the development challenges of the poor and vulnerable.
\end{abstract}

Keywords: poverty, participatory research approach, participatory wealth ranking, poor households, Zambia 


\section{Introduction}

In recent years, most African countries including Zambia have experienced high rates of economic growth. The Zambian economy has been performing relatively well, with real Gross Domestic Product (GDP) growth of over 6.0\%, respectively in the period 2001 to 2011(Central Statistical Office, 2012). The recent economic trends have generally been due to good performance of the copper mining industry buoyed by the high global copper prices. Major exports are dominated by copper and cobalt mining (73\%) and the remaining contributors - mostly agriculture, with some manufacturing and tourism. Agriculture is the major economic activity for rural households in Zambia. Farming generates food as well as cash for the farmers. For instance, agriculture alone contributed 20\% of Gross Domestic Product (GDP) in 2005, of which about $80 \%$ was a contribution from the smallholder sub-sector. Agriculture also contributes to about $60 \%$ of employment in the country (Government of the Republic of Zambia, 2011).

Despite these high rates of economic growth in Zambia, disparities between the rich and the poor continue to prevail, especially in rural areas. Currently, poverty is widespread in Zambia, with about $61 \%$ of the people in the country living below the poverty line and above half of them are considered to be in extreme poverty. Moreover, despite significant improvements in urban poverty reduction, poverty remains an acute problem for the rural people who make up the majority of the country's population with rural poverty rates being stuck at over 77 per cent for more than a decade (Central Statistical Office, 2012a).

Poverty is acknowledged to be a multidimensional phenomenon and for this reason effective measures to address poverty require conceptualizing it not only as lack of income or shortfall in expenditure required to achieve a certain minimally acceptable level of living standard, but also as lack of capabilities that individuals require in order to live meaningful and valued lives in their societies (Sen, 1992; Baulch \& Hoddinott, 2000; El Amin, 2003). However, in most countries, the available information on current levels of poverty is solely based on socio economic surveys (household, income/expenditure) that mostly yield quantitative data collected on large generalized samples of households. While this data is representative of conventional measures of poverty, it often fails to capture the multi-dimensionality of poverty, which can be crucial for strategic targeting, prioritizing and planning of interventions for addressing the development challenges of the poor and vulnerable communities especially in rural areas. This data also lacks the vital perspective of the local poor people on poverty for which poverty reduction strategies or other development interventions are meant for (Chambers, 1994; Ashong \& Smith, 2001; Van Campenhout, 2006).

As a way of addressing the shortcomings of quantitative socio-economic surveys, Participatory Wealth Ranking (PWR) has been extensively used to promote discussions on locally relevant dimensions of poverty and other public interventions (Chambers, 1994; Ashong \& Smith, 2001; Hargreaves et al., 2007; Narayan, 1997). PWR is based on the idea of utilizing local knowledge about the levels of relative poverty and wealth. Key informants rank their fellow community members into wealth categories after they have discussed in detail underlying concepts of poverty and wealth within their communities (Narayan et al., 2000; Simanowitz et al., 2000; 
Van Campenhout, 2006). In this study, PWR was used to understand the poverty situation of Zambian rural households. Therefore, the specific objective of this study was to obtain an understanding of local views on the characteristics of poor and better-off or wealthy households. In other words, the aim was to identify the key components of poverty or wealth, as understood by the rural residents.

\section{Methods}

\subsection{Study Area}

The study was conducted in the Magobbo area which is located in Mazabuka district of the Southern Province of Zambia. Mazabuka district is located about 125 kilometers from Lusaka, the capital city of Zambia. Mazabuka district is located directly south of and adjacent to the Kafue flats which is the flood plain portion of the Kafue River. As a result, the region is characterized by rich agricultural land and an economy dominated by large-scale agriculture especially sugar cane cultivation and processing. Good climate, fertile soil, water availability, and access to transport by road and rail, has made the district an optimal location for the cultivation of sugar cane as well as wheat, coffee and maize (Mazabuka District Council, 2003). The economic base of Mazabuka district is therefore dominated by commercial and subsistence agriculture. Livestock rearing also forms an important part of the agricultural sector in the district. The population of Mazabuka is estimated to be about 230,972 people with about seventy five percent (75\%) of the population living in the rural area, where there is no formal employment. The Tonga are the predominant ethnic group in Mazabuka and the rest of Southern Province (Central Statistical Office, 2012b).

The Magobbo area covers an area of about 1,800 hectares. The land is a mixture of customary and private land. Smallholder farmers, retired employees and local indigenous people, cultivate various crops for livelihoods on fields located near their homesteads. The remainder of the area is used by the community for other developments and livestock grazing. Some smallholder farmers are engaged in a variety of informal agricultural activities that tend to be short-term, seasonal and frequently unsuccessful resulting in food insecurity and general rural poverty (Whydah Consulting 2011). The Magobbo area is located about $12.5 \mathrm{~km}$ from the Zambia Sugar Plc. mill at Nakambala. Since October 2009, about 28 farmers in Magobbo have been participating in a sugarcane production outgrower scheme which is managed by Zambia Sugar Plc. Under this outgrower scheme, the Sugar Company provides training and infrastructure like the irrigation furrows for the production of the sugar cane crop by the participating farmers. Zambia Sugar Plc. buys all the crop from the participating farmers as a way of promoting local community development and employment creation.

\subsection{Methodology and Process}

Participatory Rural Appraisal (PRA) methodologies were used to engage residents in six selected communities in Magobbo. The author and two research facilitators with some experience in organizing focus group discussions conducted the PRA methods and techniques. The research facilitators were further trained in the use of the participatory research methods and techniques that were used to collect and generate large amounts of mostly qualitative data. 
Participatory research methods and techniques, including some innovative and creative tools, were used to ensure active participation of community residents in providing and generating empirical qualitative data about their communities. Face-to-face interaction and on-going dialogue with the key informants was also a key element of the data collection process.

\subsubsection{Process of Data Collection for the Participatory Wealth Ranking}

After getting informed consent from the local leadership, mainly the Headmen, community members were invited to an open meeting in the village. The author and the facilitators then introduced and explained the objective of the research project or activity to the residents. After this introduction, groups of individuals residing in defined village sections were asked to get together and draw a map of their residential area. Typically, the areas within Magobbo hold 20-30 households. The participants numbered all households on the map and provided a list of household head names or other dwelling identifiers. This process took almost the whole day ending in the late afternoon when the exercise was adjourned to be continued the following morning.

On the following day, smaller focus group discussions (FGD) were held with six to twelve local community members at a time. These were usually the household heads along with their spouses. The groups were first led in a facilitated discussion on aspects of poverty in the village. Participants were asked by the facilitator to characterize households that are "very poor", those that are "poor", those that are "better-off", and those that are "well-off". This probing or questioning was posed in turn to participants and the proceedings of the resulting discussions were captured by the facilitator in form of short statements.

Participants in the FGD were then asked to rank some randomly picked households in a given area of Magobbo from the poorest to the most well-off according to the definitions provided by the participants in the earlier discussion. The participants were asked to compare them with the other households in the area. As the process proceeded, a number of piles of similarly ranked households was generated from the poorest to the wealthiest. At the end of this process, the participants were asked to further describe the characteristics of the households in each ranking pile. Each pile was discussed in turn, and these discussions were also recorded by the facilitator.

\subsection{Data Analysis}

The large amount of qualitative data which was generated was analyzed at various levels and by the author with the assistance of the two research facilitators. While the author and the research facilitators were mainly responsible for this, community residents who participated in the focus group discussions also analyzed and interpreted the information that they provided.

Several methods and techniques were used to analyze the data that were collected. Among these were collective analysis and reflection, content analysis, causal analysis, and comparative analysis. Subjecting the data to such rigorous analyses helped to verify and validate their objectivity, reliability, and credibility and to ensure that they provide a sound understanding of local views on the characteristics of the poor and wealthy households. 


\section{Results}

The wealth ranking exercise discussions provided a rich source of information on the traits, characteristics and visible signs by which poverty is recognized in the people in Magobbo; and a number of observations emerged. During the wealth ranking exercises, nearly every villager was initially defined as "poor," in part because informants hoped that the poorest were being identified in order to provide them with a service or benefit. After explanations to the contrary, and with extended probing, it became clear that there are recognized differences among the "very poor", "the poor", "the better-off or middle class" and "the well-off or wealthy". In the understanding of the community members, poverty is viewed as a condition which can be manifestly observed by the degree or level of ownership or access to material resources. It is a condition, with clear variations or degrees from mild to extreme, that is, from "very poor" to "poor" to "better-off" to "well-off or wealthy". The community members identified the local language equivalents for these poverty or wealth categories as "bacete lokó", "bacete", "bavubi" and "bavubide lokó", respectively.

During the discussions with the community members, it was noted that there are just slight or minor differences between the "very poor" and "poor" on one hand and between the "the better-off or middle class" and "the well-off or wealthy" households on the other hand in terms of their characteristics. Since this study was focused on getting local views on the characteristics of poverty, the discussion on the socioeconomic indicators of poverty concentrates on the "very poor" and "poor" individuals and households who are at the extreme end of this condition of poverty or wealth. For purposes of contrasting, the characteristics of the "the better-off or middle class" and "the well-off or wealthy" households, are also presented.

Several characteristics or themes were identified during the wealth ranking exercises to describe the poverty or wealth status of households in Magobbo. Livelihood activities or employment status was the characteristic most regularly raised by participants in describing relative wealth characteristics. The physical assets owned, land ownership or tenure, housing conditions, food security, and schooling of children, were also regularly mentioned. Alternative ways in which income may be generated were also mentioned regularly, including self-employment, begging, as well as getting remittances from relatives. A variety of non-income characteristics were also identified, for example, the gender dimension of poverty, health and nutrition status of the households. Table 1 presents a summary of the characteristics of the very poor and well-off or wealthy households as identified during the wealth ranking exercise. 
Table 1. Characteristics of the Very Poor and Well-off Households in Magobbo Area, Mazabuka

\begin{tabular}{|c|c|}
\hline Very Poor People & Better-off and/or Well-off People \\
\hline 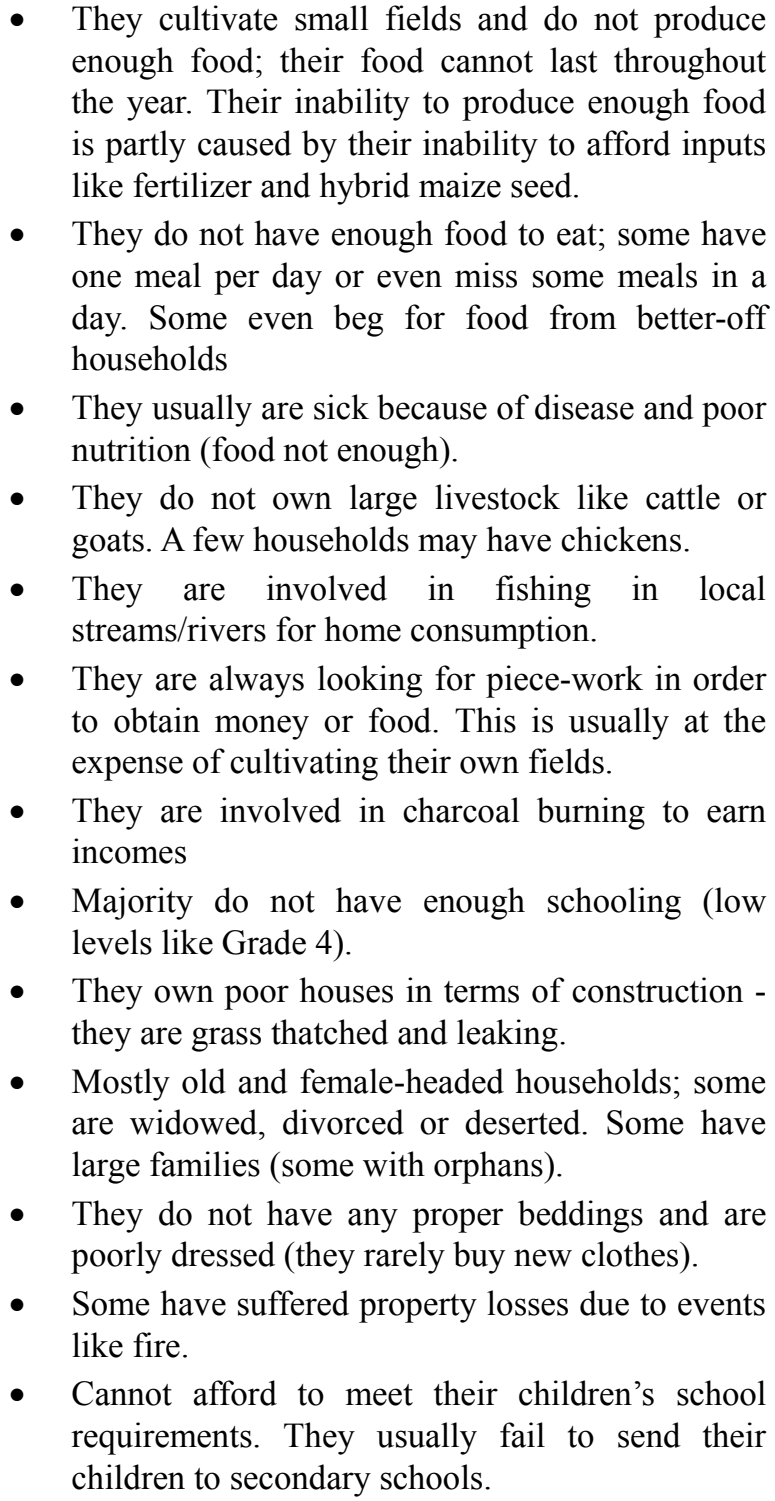 & $\begin{array}{l}\text { - They produce enough food to feed themselves } \\
\text { throughout the year. They can afford to eat two } \\
\text { and/or three meals per day. } \\
\text { - They cultivate large fields to produce crops such } \\
\text { as maize and sugar cane. They own and cultivate } \\
\text { 3-4 fields and commonly hire other community } \\
\text { members for labour to work in their fields. } \\
\text { - Own livestock like cattle, pigs, goats and chickens. } \\
\text { - Some are skilled fishermen who catch fish from } \\
\text { the local streams/rivers for home consumption and } \\
\text { local sales. } \\
\text { - Some are involved in fish trading. They buy and } \\
\text { - They have children in urban areas who remit cash } \\
\text { - } \text { to them. } \\
\text { - Some have skills such as carpentry, masonry and } \\
\text { bicycle repairing which earns them money. } \\
\text { Own assets like bicycles, radios, wheelbarrows, } \\
\text { - } \text { ploughs and scotch carts. } \\
\text { Own good constructed houses with burnt bricks, } \\
\text { - } \text { - They are well dressed and look smart. } \\
\text { They are able to afford to send their children to } \\
\text { school (secondary school) } \\
\text { Mostly male-headed households and some are } \\
\text { - }\end{array}$ \\
\hline
\end{tabular}

\subsection{The Profile of the Poor}

\subsubsection{Livelihood Activities or Employment}

Farming is the dominant economic activity for the communities in Magobbo area. The households are mainly engaged in a mixture of agricultural and non-agricultural activities as a means of living. Maize constitutes the single largest cultivated crop, which is cultivated by all the households in Magobbo. Other important crops in the area are groundnuts, cowpeas, sugar cane, soyabeans, sweet potatoes, cotton, sorghum, and millet. Households also keep livestock, like cattle, other small ruminants and poultry in addition to their crop production activities as a livelihood and risk management strategy. Livestock provide meat for direct 
household consumption and manure for crop production. On-farm income comes from the sale of both food and cash crops (sugar cane, grains, fruits and vegetables), as well as livestock and fish. Off-farm income includes cash income from both agricultural work and non-agricultural activities like self-employment, formal employment, petty trading, remittances, and others.

The well-off or wealthy households are the ones who mostly cultivate large land areas and produce surpluses for sale. In Magobbo, some of these wealthy households are involved in production of sugar cane under an outgrower scheme arrangement with the Zambia Sugar Company. After harvesting, the sugar cane is delivered to Zambia Sugar Plc. for processing. The Magobbo farmers are paid for the sugar supplied after the costs are met in accordance with the outgrower contract. Some of the well or better-off households are involved in fishing and fish trading. In addition to fishing in the local streams/rivers for home consumption, they also go to Mazabuka to buy fish which they bring back to sell in the local community. These households are also relatively more skilled in income generation as compared to the poor. For instance, they possess skills such as carpentry, masonry or bicycle repairing which they use to raise more income. Some of them also receive remittances from their children in urban areas.

On the other hand, the poor are mainly involved in subsistence farming as well as working on other people's land as labourers. The involvement of the poor as labourers on a piece work basis within and outside their respective villages is a strategy for obtaining income and food. In most cases, they are paid in-kind with food items like maize, cowpeas, groundnuts, pork, and goat meat. Their involvement in piece work also has a negative impact on the poor peoples' food security in that it is done at the expense of working in their own fields. They end up cultivating small areas and have poor yields because they spend most of their time and effort working on other people's fields. Some of the informants in the FGDs linked poverty in their community to laziness of some of the local people who are strong and healthy. They observed that some of the poor were allegedly not willing to farm or work on their land in order to take care of themselves and their families. They pointed to the fact some of the poor were willing and able to work on other people's land on a convenient agreement, and this is usually at the expense of their own farm production. The poor in Magobbo also depend on the local area forest to make charcoal or gather firewood and wild foods such as fruits, nuts and mushrooms for sale within village markets or in exchange for foodstuffs and other household goods.

\subsubsection{Land Ownership}

The land in Magobbo is a mixture of customary land and private land. As is typical in most parts of Zambia, customary land is predominant in Magobbo. Under customary tenure, generally, the land is often held by a group, community lineage or clan, family or individuals and an individual in the community may give out a piece of it to another person for use, with the local leaders' knowledge. Once acquired, land may be passed on from generation to generation. The individuals or households allocated the land do not own it but have usufructuary rights over it for their production and sustenance. Within the households, the heads (usually men) apportion the land to family members for farming and building purposes. 
The majority poor in Magobbo have access to land through customary tenure which they inherited from their parents or relatives and as well as access to communal land obtained from local chiefs and headmen. This is the land on which they cultivate their crops as well as graze their animals. On average, the households own about two fields on which they cultivate small portions of land for subsistence.

The available private land in Magobbo was converted from the customary land to accommodate the establishment of the sugarcane fields under the outgrower scheme. Individuals and entities can acquire transferable leasehold rights to land by converting their customary landholdings or approaching local authorities to identify state land available for lease, or customary land that a landholder is interested in converting to leasehold land. The 1995 Land Act requires the authorization of the chief and consent of any other person affected by the land lease for a land conversion. Local authorities apply for leases through the Commissioner of Lands, who is authorized to grant leaseholds on behalf of the Republican President.

Participation in the sugar outgrower scheme is restricted to farmers who own private land or have secure title deeds or leasehold tenure. With this condition, the local wealthy or better-off households responded and acquired title deeds to their land where they have established sugar fields. The farmers have been assisted with construction of basic infrastructure such as furrows for irrigation of the sugarcane crop. These sugarcane fields owned by these households are in addition to the regular fields on other customary land where they cultivate the traditional crops such as maize, cotton, groundnuts, millet and sorghum. The wealthy also produce tomatoes, onions, cabbages and other leafy vegetables, which they sell locally and in Mazabuka. They are able to produce enough food and even hire other people, particularly, the poor to work for them in their fields.

\subsubsection{Physical Assets Owned}

The main assets identified included the type and condition of housing and other domestic assets or appliances which give an indication of the poverty status of the household in Magobbo. Good quality housing is a status symbol, and different types of houses or dwellings exist, but the predominant type is the mud brick with grass thatching which is common among the poor. Their construction is generally sub-standard and they even leak during the rainy season. The better-off or wealthy households on the other hand own brick houses with asbestos or iron roofs. The wealthy have managed to construct these better quality houses using their own resources whereas others have been beneficiaries of the Sugar outgrower scheme which facilitated the building of these houses.

The wealthy or better-off people also differ from the poor in that they are more resource rich in terms of ownership of other physical assets. They own more assets like bicycles, radios, TVs, mobile phones, farming implements and livestock like cattle, goats, pigs and chickens as compared to their poor counterparts. The poor typically just own small radios, reed mats, simple farm implements like hoes, axes and some cooking utensils. The lack of ownership of assets among the poor is also clearly visible from the mundane such as the lack of proper beddings, clothing and footwear. People in the FGDs observed that the poor can easily be 
identified from their characteristic humble dressing of torn shoes, pants or dresses. They noted that even if salaula (second hand clothing) is readily available and supposedly affordable, the poor in Magobbo experience challenges in purchasing these for their families and hence show obvious signs of deprivation.

\subsubsection{Food Security Status}

The number and quality of meals were characteristics mentioned that described a household's wealth status. The poor people in Magobbo were generally identified as people who fail to meet their basic requirements such as food. This arises from their inability to produce enough food (mainly maize which is the staple) and income due to lack of resources like fertilizer and livestock. The problem of failure to have enough food is so critical that some poor households only have one meal in a day whilst others even beg for food from those who are better-off. The general poor nutrition of these poor households makes some of them to be chronically ill. The informants in the FGDs observed that the local people ate nsima (a semi-soft to hard porridge cooked using maize meal which is usually eaten with an accompaniment of vegetables and/or livestock products) for their main meals. The wealthy sometimes afford to eat their nsima with chicken, fish, or goat or beef products along with some vegetables whereas the poor mainly eat vegetables. Some of the poor even beg for ingredients such as cooking oil, tomatoes and onion from their neighbors to cook the vegetables for their family meals. The nsima meals which are generally affordable in the area from locally produced maize have the capacity to sustain people for long hours after eating. The poorest households usually eat one nsima meal served in the afternoon to sustain them for the rest of the day. In the evenings, they simply quench the hunger with some snacks like sweet potatoes or locally fermented sweet drinks known as chibwantu or munkoyo which is brewed using maize grits or millet.

\subsubsection{Gender Dimension}

Generally, there is equal access to resources among men and women in Magobbo. For example, the Headman or Local Chief offer land to women if they request for it. Women also have access to credit through government programmes like the Farmer Input Support Programme (FISP) which provides subsidized agricultural inputs like seed and fertilizers to vulnerable but viable farm households. However, some groups of women such as widows, divorcees and those who have been deserted by their husbands tend to be economically disadvantaged due to loss of support and income from their men. People in FGDs noted that in most of the villages in Magobbo, the poor are more likely to be old and/or female-headed households who have large families (including orphans) to look after. The female-headed households are composed of widows or women who have been deserted by their husbands. With widowhood or desertion, the women are left with the heavy burden of feeding and raising the children alone. The women fail or struggle to meet their basic needs like food, clothes and sending children to school after desertion or death of their husbands. 


\subsubsection{Education}

Household head level of education attainment and ability to send children to school were mentioned as indicators of household wealth. The wealthy or better-off households are relatively more educated as compared to the poor. Informants in the FGDs observed that most of the wealthy household heads have attained at least some secondary school education (Grade 12) whereas the majority of the poor household heads have limited school attainment (Primary level). The wealthy household also possess skills such as carpentry or masonry which they acquired from some trade schools as well as from work experience. The betteroff households can afford to send their children to secondary schools (where fees or levies are charged). Some of the wealthy send their children to public boarding secondary schools in other districts. On the other hand, it was observed that in general the poor households were mostly struggling and unable to afford education of their children beyond the primary school level (Grade 7). The children of the poor households usually attended public primary schools within Magobbo area. The children of the poor households also experience challenges to acquire school requisites and learning materials such as uniforms or books. It was observed during the FGDs that it is common to find that some of the children from poor households only had a single notebook for all school subjects. This tends to be demoralizing for most of the children and most of them drop out of school at an early age. Some key informants indicated that some of the poorest households did not even allow their children to obtain any formal education but rather let them accompany and assist them in their livelihood activities. For instance, the poorest households involved their children in working with them when they get piece work in fields or sent them to sell commodities like charcoal in the villages to supplement household income.

\section{Discussion}

The finding of this study which utilized the participatory wealth ranking (PWR) process has provided a qualitative understanding of community defined indicators of poverty in rural Zambia. The findings are also similar or consistent with findings from several other studies elsewhere which have clarified the multi-dimensionality of poverty and reflects the broader work carried out by the 'Voices of the Poor' exercises across several countries, where poverty or ill-being was identified as being complex and interwoven, including a material lack and need for shelter, assets, money and often characterized by hunger, pain, discomfort, exhaustion, social exclusion, vulnerability, powerlessness and low self-esteem (Narayan et al., 2000; Aryeetey et al., 2013). In this context, and as reflected through other literature, poverty was identified as a composite of both personal and community life situations where on the personal level, poverty is reflected in an inability to gain access to basic community services (Francis et al., 1997; Batse et al., 1999).

The views or concepts expressed by the people in Magobbo who were interviewed for this study regarding poverty and well-being are similar to those findings produced from other studies using participatory techniques. Several qualitative assessments of poverty in most developing countries have revealed that the poor are characterized both in terms of their occupation and their lack of access to assets and social services (Aryeetey et al., 2013; 
Narayan, 1997). Physical capital assets, such as housing type, sanitation, sources of drinking water and cooking are often used as proxy indicators of household well-being. A related indicator, the construction materials of dwellings, reflects the expected poverty profile. Poorer households were found to occupy dwellings made of mud or mud-bricks, whilst the non-poor occupy dwellings made of stone/burnt-bricks or cement. As the poorest occupational group, those engaged in agricultural activities tend to live in mud/mud-bricked dwellings, whilst those in the formal sector tend to live in brick/ cement dwellings, reflecting both well-being and to a certain extent, level of rurality (Francis et al., 1997; Kay et al., 2003). More broadly, the poor in the 'Consultations With The Poor' (CWTP) exercises were defined as those who have no place to sleep and no property in any form, in contrast to the very rich who own, or have access to a considerable array of physical assets, both domestically (housing, cars etc.) and in business (farms, enterprises, etc.). Improvements in physical assets measured over time are considered to be a sign of increasing well-being, with for example, the replacement of thatched by aluminium roofing defined in rural communities as a characteristic of those 'on the way to becoming rich' (Kunfaa, 1999; Van Campenhout, 2006; Robles-Zavala \& Fiechter-Russo, 2008).

Several other studies on the characteristics or causes of poverty have focused particularly on agricultural and environmental factors amongst the rural poor. Low yields, food insecurity, infertile land, lack of rains and bush fires were all mentioned in rural assessments, whilst the urban poor tended to highlight factors such as unemployment, lack of money and illness. The degree of reliance upon the environment for the majority of rural dwellers, and notably the poor who often lack the resources to diversify their livelihood base, explains the level of concern over access to natural capital (Francis et al., 1997; Kunfaa, 1999; Robles-Zavala \& Fiechter-Russo, 2008). Findings from these studies revealed that typically food crop farmers were amongst the poorest of the poor, although those engaged in vegetable production were better-off, with the sale of oil palm, cocoa and citrus fruits providing cash or in-kind income. The study finding in Magobbo are also consistent with these studies as was noted that the better-off households produce cash crops like sugarcane whereas the poor households even struggle to produce food crops. Older people, especially those unable to continue farming were noted as being largely dependent upon their children for labour and financial support. Remittances from children abroad were often perceived to be a characteristic of relative well-being, although several older community members stated that they received no such support (Francis et al., 1997; Ashong \& Smith, 2001; Kay et al., 2003).

Some studies have also found that amongst women, poverty was often associated with lack of access to land, particularly amongst the older generation, due to old age, physical weakness or the loss of land after a husband's death. Good access to land within the communities studied related primarily to high socio-political status, e.g. family member of the royal family or a respected elder (Ashong \& Smith, 2001; Kay et al., 2003). For the poor in particular, accessing physical capital assets such as fuel wood for cooking and lighting, water for cooking and drinking are time and energy burdensome activities, predominantly carried out by women. This is a particular facet and cause of rural poverty, with women engaged in lengthy trips to access these resources, taking time away from agriculturally productive 
activities (Ashong \& Smith, 2001). The finding from this study which clearly shows that women or female-headed households tend to be poorer in comparison with male-headed households is equally consistent with findings from these other studies.

Lack of social capital, or social exclusion, has also been highlighted as a significant characteristic of poverty during some studies (Narayan, 1997; Aryeetey et al., 2013; Kay et al., 2003). Support from family networks was found to be varied, including accommodation, food, money and other resources to initiate enterprises. Amongst these, the most important relationships were identified as parent-child and marriage. Marriage for women can improve access to land, through the husband's family land. In this context, unmarried, divorced or widowed young and elderly women were identified as the most vulnerable, lacking these important networks. The findings from this study about these issues of social capital and how they affect vulnerability of women are also consistent with these studies which were conducted in Tanzania, Ghana and Ethiopia.

Some of the rural studies done through 'Consultations With the Poor' (CWTP), identified ill-health, sickness and illness as amongst the most common, self-determined causes of poverty. Others included unemployment, lack of education, poor soils and lack of financial capital. Ill-health was the most commonly identified manifestation of poverty in rural areas. Furthermore, the studies identified physical and psychological ill-health as both, in-part, cause and consequence of poor well-being or poverty (Kunfaa, 1999; Narayan et al., 2000; Aryeetey et al., 2013). Whilst those who descend into (or remain in) poverty as a consequence of ill-health are clearly likely to remain in this physical or mental state, lacking the resources to seek assistance, the implication of ill-health as an outcome of poverty also implies that poverty caused by other factors (lack of financial capital, poor or no employment etc.) can also cause ill health amongst those who were previously well (Aryeetey et al., 2013).

In summary, this study and most studies (Hargreaves et al., 2007; Narayan, 1997; Narayan et al., 2000; Ashong \& Smith, 2001; Aryeetey et al., 2013) have shown that the concept of poverty is multidimensional and that self-characterization of poverty, gathered from the poor themselves, has become increasingly important in our understanding of poverty. Including the 'voices of the poor' to understand poverty has shown that households that were "poor" and "very poor" were characterized by descriptions of well-being indicating a genuine struggle to survive including a need to beg, limited access to food and housing and almost no access to formal employment. Some "poor" households were engaged in poorly remunerated livelihood activities such as selling charcoal and firewood. The "very poor" also exhibit ill-health and tend to be socially excluded and are marginalized in their communities.

\section{Conclusion}

The results of this study have clearly shown that the use of Participatory Wealth Ranking (PWR) exercises among rural community members has great utility in gaining an understanding of their conceptualization of poverty and its characteristics. This local knowledge can be complementary and could help to strengthen the interpretation of quantitative or money metric measurements of poverty which are typically generated from 
surveys. The results show that the rural residents are clearly able to identify several characteristics or themes to describe the poverty or wealth status of households in their communities. Livelihood activities or employment status was identified by the residents as one of the main characteristic in describing the relative poverty or wealth status of households. The physical assets owned; land ownership or tenure; housing conditions; food security; schooling of children; and alternative income generation activities such as getting remittances from relatives were also identified. A variety of other non-income characteristics were also identified such as the gender dimension of poverty, as well as the health and nutrition status of the households. This kind of information based on local views or perceptions about the key indicators or characteristics of poverty in rural areas can be valuable in making decisions related to identifying, targeting, planning and prioritizing of interventions for addressing the challenges affecting the poor.

\section{Acknowledgement}

This research was financed by a grant provided by the Organization of Social Science Research in Eastern and Southern Africa (OSSREA).

\section{References}

Aryeetey, G. C., Jehu-Appiah, C., Kotoh, A. M., Spaan, E., Arhinful, D. K., Baltussen, R., van der Geest, S., \& Agyepong, I. A. (2013). Community concepts of poverty: an application to premium exemptions in Ghana's National Health Insurance Scheme. Globalization and Health, 9(1), 12. http://dx.doi.org/10.1186/1744-8603-9-12

Ashong, K., \& Smith, D. R. (2001). Livelihoods of the Poor in Ghana: A Contextual Review of Ghana-wide definitions and trends of poverty and the poor with those of peri-urban Kumasi. Retrieved December 9, 2013, from http://www.ucl.ac.uk/dpu-projects/drivers_urb_change/urb_society/pdf_liveli_vulnera/DFID _Ashong_livelihoods_urban_transition_Kumasi_Ghana.pdf

Batse, Z. K. M., Botschie, G., \& Agyemang-Mensah, N. (1999). Integrating Capacity Building within the Context of Social Policies for Poverty Reduction in Ghana. RRPS/AOC SPRN/WCA. Retrieved January 6, 2014, from http://ibrarian.net/navon/page.jsp?paperid= $17020043 \&$ searchTerm $=$ ghana + poverty

Baulch, B., \& Hoddinott, J. (2000). Economic mobility and poverty dynamics in developing countries. The Journal of Development Studies, 36(6), 1-24. http://dx.doi.org/10.1080/00220380008422652

Central Statistical Office (CSO). (2012a). Living conditions monitoring survey report 2006 and 2010. Central Statistical Office, Lusaka, Zambia. Retrieved December 10, 2013, from http://www.zamstats.gov.zm

Central Statistical Office (CSO). (2012b). 2010 Census of Population and Housing: Volume 11- National Descriptive Tables. Central Statistical Office, Lusaka, Zambia. Retrieved December 10, 2013, from http://www.zamstats.gov.zm 
Chambers, R. (1994). The origins and practice of participatory rural appraisal. World Development, 27(7), 953-969. Retrieved December 11, 2013, from http://dx.doi.org/10.1016/0305-750x(94)90141-4

El Amin, K. A. (2003). Understanding and Combating Poverty: A Quest for Conceptualization, Measurement Indicators, Causes, and Empirical Methodologies. Economic Research Forum Working Paper 0338. Retrieved December 9, 2013, from http://www.erf.org.eg/CMS/uploads/pdf/0338_final.pdf

Francis, P. A., Milimo, J. T., Njobvu C. A., \& Tembo, S. P. M. (1997). Listening to Farmers: Participatory Assessment of Policy Reform in Zambia's Agriculture Sector. Retrieved January 15, 2014, from http://elibrary.worldbank.org/doi/book/10.1596/0-8213-4025-5

Government of the Republic of Zambia. (2011). Sixth National Development Plan 2011 2015: Sustained Economic Growth and Poverty Reduction, Lusaka, Zambia. Retrieved December 10, 2013, from http://siteresources.worldbank.org/INTZAMBIA/Resources/SNDP_Final_Draft_20_01_201 1.pdf

Hargreaves, J. R., Morrison, L. A., Gear, J. S. S., Makhubele, M. B., Porter, J. D. H., Busza, Watts, C., Kim, J. C., \& Pronyk, P. M. (2007). "Hearing the Voices of the Poor": Assigning Poverty Lines on the Basis of Local Perceptions of Poverty. A Quantitative Analysis of Qualitative Data from Participatory Wealth Ranking in Rural South Africa. World Development, 35(2), 212-229. http://dx.doi:10.1016/j.worlddev.2005.10.021

Kunfaa, E. Y. (1999). 'Consultations with the Poor', Ghana Country Synthesis Report, Centre for the Development of People (CEDEP), Kumasi, Ghana. Report commissioned by the World Bank. Accra: The World Bank. Retrieved December 10, 2013, from http://siteresources.worldbank.org/INTPOVERTY/Resources/335642-1124115102975/15551 99-1124138866347/Ghana.pdf

Mazabuka District Council (MDC). (2003). Situational analysis for Mazabuka District. Mazabuka: MDC.

Narayan, D. (1997). Voices of the Poor: Poverty and Social Capital in Tanzania. World Bank: Washington. http://dx.doi.org/10.1596/0-8213-4061-1

Narayan, D., Patel, R., Schafft, K., Rademacher, A., \& Koch-Schulte, S. (2000). Can Anyone Hear Us?: Voices of the Poor. World Bank: Washington. http://dx.doi.org/10.1596/0-1952-1601-6

Robles-Zavala, E., \& Fiechter-Russo, T. (2008). Qualitative Study of Perceptions on Poverty and Present Status of Assets in a Mayan Community in the Yucatan Peninsula. Universidad y ciencia, 24(3), 191-204. Retrieved May 25, 2014, from http://www.publicaciones.ujat.mx/publicaciones/uciencia/diciembre2008/4-373.pdf

Sen, A. K. (1992). Inequality Reexamined. Cambridge, Mass.: Harvard University Press. Retrieved from http://dx.doi.org/10.1017/s0143814x00005638 
Sharp, K., Devereux, S., \& Amare, Y. (2003). Destitution in Ethiopia's Northeastern Highlands (Amhara National Regional State). Institute of Development Studies at the University of Sussex. Retrieved December 11, 2013, from http://reliefweb.int/sites/reliefweb.int/files/resources/4B99BCC13144B864C1256D660057D EE8-scfuk-eth-17jul.pdf

Simanowitz, A., Nkuna, B., \& Kasim, S. (2000). Overcoming the obstacles of identifying the poorest families, in Microcredit Summit Campaign. Sussex: Institute for Development Studies; 2000.

Van Campenhout, B. (2006). Locally Adapted Poverty Indicators Derived from Participatory Wealth Rankings: A Case of Four Villages in Rural Tanzania. http://dx.doi.org/10.1093/jae/ej1041

Whydah Consulting. (2011). Interim Evaluation of the Magobbo Sugar Cane Outgrowers Project. Draft Report.

\section{Copyright Disclaimer}

Copyright for this article is retained by the author(s), with first publication rights granted to the journal.

This is an open-access article distributed under the terms and conditions of the Creative Commons Attribution license (http://creativecommons.org/licenses/by/3.0/). 